\title{
Occurrence of Helicobacter Pylori in Specimens of Chronic Gastritis and Gastric Adenocarcinoma Patients: A Retrospective Study at University Teaching Hospital, Kigali, Rwanda
}

\author{
Theoneste Nizeyimana ${ }^{a}$, Belson Rugwizangoga, ${ }^{a}$ bFelix Manirakiza, ${ }^{a}, b$ Alvaro C \\ $\operatorname{laga}^{a, c}$ \\ aDepartment of Clinical Biology, School of Medicine and Pharmacy, College of Medicine and Health Sciences, University of Rwanda, Kigali, \\ Rwanda; bepartment of Pathology at University Teaching Hospital of Kigali, Kigali, Rwanda; 'Department of Pathology, Brigham and Women's \\ Hospital, Boston, Massachusetts, United States of America \\ Correspondence to: Theoneste Nizeyimana (nizeyitheo2007@gmail.com)
}

\begin{abstract}
Introduction: Helicobacter pylori (H. pylori) infection is the major cause of gastroduodenal diseases in populations of different ages. We conducted aretrospective studyusing archived tissue samples to determine the prevalence of $\mathrm{H}$. pylori infection among patients diagnosed with gastritis and gastric adenocarcinoma by histopathology cases in one hospital in Rwanda.

Materials and methods: Cases of chronic gastritis and gastric adenocarcinoma histologically diagnosed in a tertiary hospital in Rwanda over the period of 2016-2018 were studied for the presence of $\mathrm{H}$. pylori using immunohistochemistry. Diagnosis of positive cases considered immunoreactivity as well as bacterial morphology, including spiral, rod-shaped, angulated and coccoid forms.

Results: Three hundred and seven cases were included in this study; chronic gastritis and gastric adenocarcinoma representing $39 \%$ and $61 \%$, respectively. The overall frequency of $\mathrm{H}$. pylori infection was $77.5 \% 180 \%$ among chronic gastritis cases versus $76 \%$ among gastric adenocarcinoma cases). Prevalence of $H$. pylori infection in chronic gastritis and adenocarcinoma did not significantly associate with age and sex.

Conclusion: The prevalence of H. pylori was high among chronic gastritis and gastric adenocarcinoma cases in Rwanda. Pathologists should investigate the presence of $\mathrm{H}$. pylori in gastric biopsies. Our data shows immunohistochemistry method is feasible and adequate to facilitate detection of $\mathrm{H}$. pylori, which may guide timely treatment.
\end{abstract}

\section{BACKGROUND}

Helicobacter pylori (H. pylori) is a gramgastroduodenal diseases in humans including chronic gastritis and gastric cancer. ${ }^{1-3}$ Approximately 95\% of gastric cancers are adenocarcinomas, which are further histologically categorized into diffuse and intestinal subtypes. ${ }^{4}$ The prevalence of $H$. pylori is approximately $50 \%$ of the adult people worldwide. ${ }^{5-7}$ The prevalence is much higher in populations of low socioeconomic status and hygiene level, compared to the developed countries. ${ }^{8-11}$ Accordingly, the prevalence of $H$. pylori infection is nearly $30 \%$ in the United States of America (USA) adult population, compared to up to $92 \%$ in some African regions. ${ }^{7,12-}$

${ }^{14}$ This epidemiological trend may explain the overrepresentation of gastric adenocarcinoma among developing countries (more than $50 \%$ of new cases) compared to the developed countries. ${ }^{4,15-18}$

Chronic atrophic gastritis is the earliest pathologic change due to $H$. pylori colonization, and it may eventually lead to gastric cancer. ${ }^{2,13,19,20}$ In H. pyloriinfected individuals, other factors contributing to chronic atrophic gastritis and cancer include the age at the time of primary infection, as well as the presence of cytotoxin-associated gene A (cagA)-positive $H$. pylori. ${ }^{21}$ The prevalence of $H$. pylori infection increases with age, being close to $80 \%$ among individuals above 70 , whereas it is around $50 \%$ in children. ${ }^{20,22,23}$

Several diagnostic tests are used in the detection of $H$. pylori infection. These include blood serum test, stool antigen test, rapid urease test, urea breath test, detection of $H$. pylori in histopathology specimens, and culture. $5,8,11,12,24$ Histopathology has been shown to have excellent sensitivity and specificity $(95 \%$ and $99 \%$, respectively), particularly with the use of special and immunohistochemical stains ${ }^{25}$ and it provides additional information about the morphology of the gastric mucosa. ${ }^{12,22-24}$ Accordingly, endoscopic biopsiesare used for screening of gastriccarcinoma. $8,16,22,26$ The prevalence of gastroduodenal disease in Rwanda is high, and a recent study using modified rapid urea- 
se testing during endoscopy showed $75 \%$ positivity for $H$. pylori. ${ }^{27}$ Using immunohistochemistry method, this study was performed to determine the frequency of occurrence of $H$. pylori infection in histopathological specimens of patients with chronic gastritis or gastric adenocarcinomain a large teaching hospital of Rwanda.

\section{MATERIALS AND METHODS}

\section{Study Design and Description}

A retrospective descriptive study was conducted in the Anatomical Pathology unit of University Teaching Hospital of Kigali (CHUK). Cases diagnosed as chronic gastritis and gastric adenocarcinoma from 2016 to 2018 were included in this study. Clinical and demographic information and formalin-fixed, paraffin-embedded (FFPE) tissue blocks, and glass slides were retrieved from the archives.

For cases with multiple biopsies from the same patient, the tissue sample with more representative lesion tissue was used. Glass slides were reviewed by 2 independent pathologists to confirm the diagnosis of chronic gastritis or gastric adenocarcinoma. All cases diagnosed as gastric ulcers, gastritis with intestinal metaplasia and/or atrophic gastritis, and chronic gastritis not otherwise specified were included. Sections of tissues with lesion (gastritis or adenocarcinoma) were selectedforimmunohistochemistry. Patients who met the inclusion criteria, but whose tissue blocks were damaged were excluded.

\section{Helicobacter pylori detection}

Sections (4 $\mu \mathrm{m}$ in thickness) were cut and prepared on charged, frosted glass slides. Immunohistochemistry using a rabbit polyclonal anti- $H$. pylori antibody (DAKO) and the Envision (DAKO) polymer detection system, with diaminobenzidine chromogen and immune-peroxidases according to the manufacturer's specifications was performed. Positive and negative controls were evaluated for each immunostaining assay. Two independent pathologists and one trainee reviewed the immunestained slides using light microscopes. In case of discrepancy, cases were reviewed and discussed, and the consensus diagnosis agreed by all pathologists. Positivity was ascertained taking into account the presence of immunoreactivity and morphology including spiral, rodshaped, angulated, and coccoid forms.

\section{Data management and statistical analysis}

Clinical, demographic, and histopathologic diagnosis, including $H$. pylori status, were compiled into a Microsoft Excel sheet. Each patient was assigned an identification code to maintain patients' confidentiality. The data was imported into and analyzed using the Statistical Product and Service Solutions(IBM SPSS). Fisher's exact test was used to compare proportions. A two-tailed $P$ value <.05 was considered significant.

\section{Ethical Considerations}

This study was approved by the University of Rwanda (UR), College of Medicine and Health Sciences (CMHS) Institutional Review Board (IRB), approval number 455/ CMHS IRB/2019. Permission to access the data was provided by the administration of the hospital.

\section{RESULTS}

\section{Patients and Disease Characteristics}

Most 197(64.2\%) patients with chronic gastritis and gastric adenocarcinoma were older than 50 (range $=15$ to 92, mean=55, median=57) years (Table 1). All the regions of Rwanda are represented, with a slightly higher proportion of patients residing in Kigali City $72(23.5 \%)$. Most $264(86 \%)$ biopsies were endoscopic and almost all $(98.4 \%)$ were taken from the non-cardial (distal) part of the stomach and $61 \%$ of cases were diagnosed with gastric adenocarcinoma, with a predominance of intestinal type gastric adenocarcinoma (Table 1). Figure 1 illustrates the routinely stained sections of gastric adenocarcinoma (Figure 1.A-B) and chronic gastritis (Figure 1.C), as well as the various morphologies of $H$. pylori as detected using immunohistochemistry (Figure 1.D-F).

\section{Biological behavior of chronic gastritis and gastric adenocarcinoma}

The prevalence of $H$. pylori infection was $80.2 \%$ and $75.8 \%$ in chronic gastritis and gastric adenocarcinoma, respectively (Table 2), but there was no significant difference in the number of cases with $H$. pylori infection when comparing chronic gastritis and gastric adenocarcinoma groups of patients $(P=0.371)$. Moreover, the type of gastric adenocarcinoma showed no correlation with $H$. pylori infection $(P=0.732)$.

The frequency of presence of $H$. pylori in the reviewed biopsies did not varies with the types of studied gastroduodenal diseases (chronic gastritis and adenocarcinoma), age and sex (Table 2).

\section{FIGURE 1. Morphology of gastric adenocarcinoma, chronic gastritis and $\mathrm{H}$. pylori}

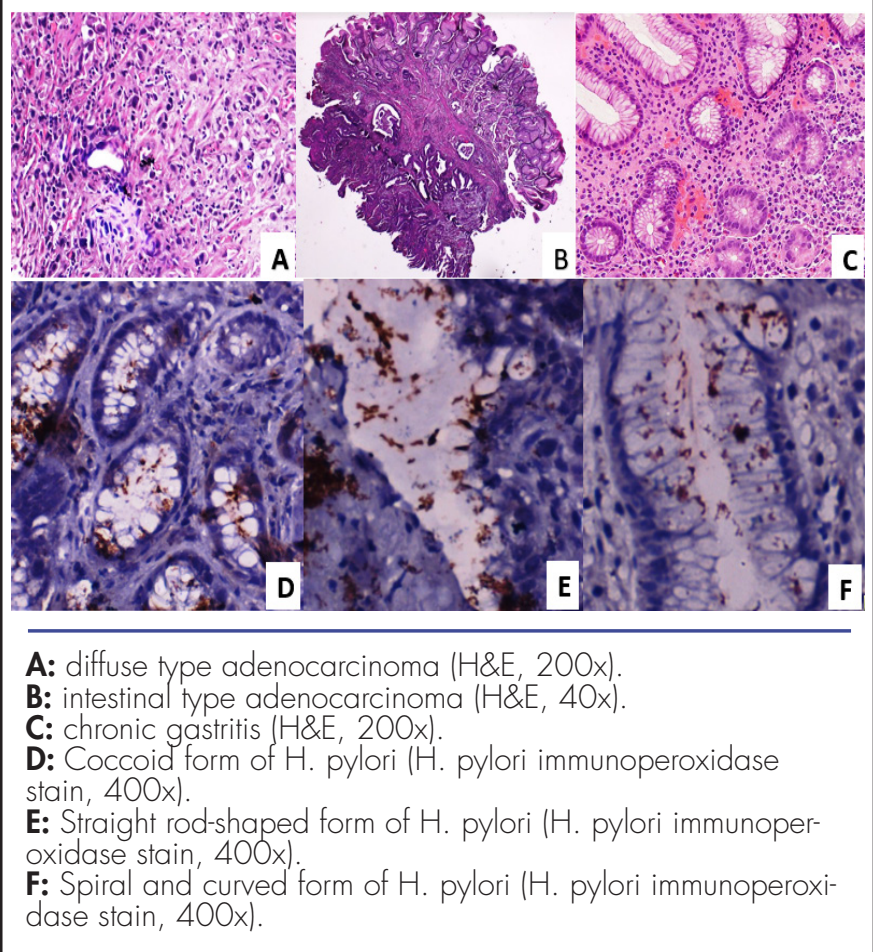




\begin{tabular}{|c|c|c|}
\hline \multicolumn{3}{|c|}{$\begin{array}{l}\text { TABLE 1: Clinical, Demographic and Pathological } \\
\text { Characteristics of } 307 \text { Patients with Chronic Gastritis } \\
\text { and Gastric Adenocarcinoma }\end{array}$} \\
\hline Characteristics & $\mathbf{n}$ & $\%$ \\
\hline \multicolumn{3}{|l|}{ Age (years, n=307) } \\
\hline$\leq 50$ & 110 & 35.8 \\
\hline$>50$ & 197 & 64.2 \\
\hline \multicolumn{3}{|l|}{ Sex $(n=307)$} \\
\hline Male & 153 & 49.8 \\
\hline Female & 154 & 50.2 \\
\hline \multicolumn{3}{|l|}{ Residence (n=307) } \\
\hline Kigali city & 72 & 23.5 \\
\hline East & 64 & 20.4 \\
\hline North & 61 & 19.9 \\
\hline South & 56 & 18.2 \\
\hline West & 50 & 16.3 \\
\hline Foreigners & 2 & 0.7 \\
\hline \multicolumn{3}{|l|}{ Anatomical site $(n=307)$} \\
\hline Cardia & 5 & 1.6 \\
\hline Non-cardia & 302 & 98.4 \\
\hline \multicolumn{3}{|l|}{ Specimen type ( $n=307)$} \\
\hline Resection specimens & 43 & 14.0 \\
\hline Endoscopic biopsies & 264 & 86.0 \\
\hline \multicolumn{3}{|l|}{ Diagnosis ( $n=307$ ) } \\
\hline Chronic gastritis & 121 & 39.4 \\
\hline Gastric adenocarcinoma $(n=196) 196$ & 60.6 & \\
\hline Intestinal type & 104 & 55.9 \\
\hline Diffuse type & 63 & 33.9 \\
\hline Mixed type & 19 & 10.2 \\
\hline \multicolumn{3}{|l|}{ H. pylori status ( $n=307$ ) } \\
\hline Positive & 238 & 77.5 \\
\hline Negative & 69 & 22.5 \\
\hline
\end{tabular}

\section{DISCUSSION}

H. pylori plays a major role in gastrointestinal diseases including chronic gastritis, gastroduodenal ulcers, and gastric adenocarcinoma and MALT lymphoma. Previous studies have shown that immunohistochemistry is a sensitive and reliable test for identifying $H$. pylori infection in tissue sections. ${ }^{13,25}$ In the present study, we analyzed the proportion of $H$. pylori infection among pathology samples of patients diagnosed with chronic gastritis and gastric adenocarcinomain one of the hospitals in Rwanda.

The high proportion of endoscopic biopsies $(86 \%)$ in our cohort is in keeping with the fact that endoscopic biopsy is considered a gold standard procedure for the screening and the detection of gastric cancer. ${ }^{1,20}$ In both patient groups, the majority of cases were older than 50 years of age, while both sexes were almost equally represented. The relatively over-representation of Kigali and the Eastern regions among the cohort may be explained by the geographical accessibility to the study site.

The overall prevalence of $H$. pylori infection among both disease groups was high $(77 \%)$. Asimilarproportion $(75 \%)$ of $H$. pylori infection (using modified rapid urease test) was previously reported in Rwanda, in a study comprising all patients who underwent upper gastrointestinal endoscopy. The proportions, although slightly different, are not significantly different. ${ }^{27}$ The proportion of $H$. pylori infection among various cohorts of individuals in Africa ranges from 55 to $92 \% .{ }^{11,14}$ In addition, there was no significant difference in the rates of $H$. pylori infection between chronic gastritis and gastric adenocarcinoma $(P=0.371)$. These findings are similar to those previously reported in other settings. ${ }^{14}$

In the present study, although there was no significant association between age (using a 50-year cut-off) and H. pylori infection, a trend towards a higher proportion of $H$. pylori infection with increasing age among chronic gastritis patients was observed. In contrast, it tends to de-

TABLE 2: Correlation Between H. Pylori and Clinical and Demographic Characteristics Of Patients With Chronic Gastritis and Gastric Adenocarcinoma

\begin{tabular}{lllll}
\hline Parameter & Characteristics & \multicolumn{2}{l}{ H. pylori positive } & Fisher's exact test \\
& & Yes & No & \\
\hline Dalue
\end{tabular}


crease with increasing age among gastric adenocarcinoma patients. These findings are consistent with the previous studies which reported that $H$. pylori infection is typically universal in all adulthood age groups ${ }^{20,28}$, because it is up taken during youthfulness and generally persists during lifetime except if correctly managed. ${ }^{29}$

\section{CONCLUSION}

This study documents a high prevalence of $H$. pylori infection in pathology specimens at one major hospital in Rwanda. Study findings indicate that all age and both sexes are at risk of getting $\mathrm{H}$. pylori infection, and suggest that pathologists should consider using immunohistochemistry in the evaluation of gastric biopsies. This may allow early detection and appropriate treatment, and hence decrease the risk of gastric cancer.

\section{REFERENCES}

1. Alfarouk KO, Bashir AHH, Aljarbou AN, Ramadan AM, Muddathir AK, AlHoufie STS, et al. The Possible Role of Helicobacter pylori in Gastric Cancer and Its Management. Front Oncol. 2019;9:75-. DOl: 10.3389/fonc.2019.00075.

2. Díaz P, Valenzuela Valderrama M, Bravo J, Quest AFG. Helicobacter pylori and Gastric Cancer: Adaptive Cellular Mechanisms nvolved in Disease Progression. Frontiers in microbiology. 2018;9:5-. DOI: 10.3389/fmicb.2018.00005.

3. Daniyal M, Ahmad S, Ahmad M, Asif HM, Akram M, Ur Rehman $S$, et al. Risk Factors and Epidemiology of Gastric Cancer in Pakistan. Asian Pac J Cancer Prev. 20 15; 16(12):4821-4. DOl: 10.7314/apicp.2015.16.12.4821.

4. Rawla P, Barsouk A. Epidemiology of gastric cancer: global trends, risk factors and prevention. Prz Gastroenterol. 2019; 14(1):2638. DOl: 10.5114/pg.2018.80001.

5. Talebi Bezmin Abadi A. Diagnosis of Helicobacter pylori Using Invasive and Noninvasive Approaches. J Pathog. 2018;2018:9064952-. DOl: 10.1155/2018/9064952.

6. Basílio ILD, Catão MFC, Carvalho JDS, Freire-Neto FP, Ferreira $L C$, Jerônimo SMB. Risk factors of Helicobacter pylori infection in an urban community in Northeast Brazil and the relationship between the infection and gastric diseases. Rev Soc Bras Med Trop. 2018;51(2): 183-9. DOI: 10.1590/0037-8682-04122016.

7. Bosch DE, Krumm N, Wener MH, Yeh MM, Truong CD, Reddi DM, et al. Serology Is More Sensitive Than Urea Breath Test or Stool Antigen for the Initial Diagnosis of Helicobacter pylori Gastritis When Compared With Histopathology. American journal of clinical pathology. 2020;154(2):255-65. DOI: 10.1093/ aicp/aqaa043.

8. Wang Y-K, Kuo F-C, Liu C-J, Wu M-C, Shih H-Y, Wang SSW, et al. Diagnosis of Helicobacter pylori infection: Current options and developments. World J Gastroenterol. 2015;21 (40): 11221-35. DOI: 10.3748/wig.v21.i40.11221

9. Matta AJ, Pazos AJ, Bustamante-Rengifo JA, Bravo LE. Genomic variability of Helicobacter pylori isolates of gastric regions from two Colombian populations. World J Gastroenterol. 2017;23(5):800-9. DOl: 10.3748/wig.v23.i5.800.

10. Graham DY. History of Helicobacter pylori, duodenal ulcer, gastric ulcer and gastric cancer. World J Gastroenterol. 2014;20(1 8):5191-204. DOl: 10.3748/wig.v20.i18.5191.

11. Hooi JKY, Lai WY, Ng WK, Suen MMY, Underwood FE, Tanyingoh D, et al. Global Prevalence of Helicobacter pylori Infection: Systematic Review and Meta-Analysis. Gastroenterology. 2017; 153(2):420-9. DOI: 10.1053/i.gastro.2017.04.022.
12. Lee JY, Kim N. Diagnosis of Helicobacter pylori by invasive test: histology. Ann Transl Med. 2015;3(1):10-. DOI: 10.3978/i. issn.2305-5839.2014.11.03.

13. Hunt RH, Xiao SD, Megraud F, Leon-Barua R, Bazzoli F, van der Merwe S, et al. Helicobacter pylori in developing countries. World Gastroenterology Organisation Global Guideline. j Gastrointestin Liver Dis. 2011 ; 20(3):299-304.

14. Asombang AW, Rahman R, Ibdah JA. Gastric cancer in Africa: current management and outcomes. World J Gastroenterol. 2014;20(14):3875-9. DOI: 10.3748/wig.v20.i14.3875.

15. Sitarz R, Skierucha M, Mielko J, Offerhaus GJA, Maciejewski $R$ Polkowski WP. Gastric cancer: epidemiology, prevention, classification, and treatment. Cancer Manag Res. 20 1 8; 10:23948. DOI: 10.2147/CMAR.S149619.

16. Karimi P, Islami F, Anandasabapathy S, Freedman ND, Kamangar F. Gastric cancer: descriptive epidemiology, risk factors, screening, and prevention. Cancer epidemiology, biomarkers \& prevention: a publication of the American Association for Cancer Research, cosponsored by the American Society of Preventive Oncology. 2014;23(5):700-13. DOI: 10.1158/1055-9965. EPI-13-1057

17. Shiota S, Thrift AP, Green L, Shah R, Verstovsek G, Rugge M, et al. Clinical Manifestations of Helicobacter pylori-Negative Gastritis. Clinical gastroenterology and hepatology : the official clinical practice journal of the American Gastroenterological Association. 2017;15(7): 1037-46.e3. DOI: 10.1016/i. cgh.2017.01.006.

18. Siegel RL, Miller KD, Jemal A. Cancer statistics, 2020. CA Cancer J Clin. 2020;70(1):7-30. DOI: 10.3322/caac.21590.

19. Ohata H, Kitauchi S, Yoshimura N, Mugitani K, Iwane M, Nakamura $H$, et al. Progression of chronic atrophic gastritis associated with Helicobacter pylori infection increases risk of gastric cancer. Int J Cancer. 2004;109(1):138-43. DOl: 10.1002/ijc. 11680.

20. Kuipers EJ. Review article: exploring the link between Helicobacter pylori and gastric cancer. Aliment Pharmacol Ther. 1999; 13 Suppl 1:3-1 1. DOI: 10.1046/i.1365-2036.1999.00002.x.

21. Subsomwong $P$, Miftahussurur $M$, Uchida T, Vilaichone R-K, Ratanachu-Ek T, Mahachai V, et al. Prevalence, risk factors, and virulence genes of Helicobacter pylori among dyspeptic patients in two different gastric cancer risk regions of Thailand. PloS one. 2017; 12(10):e0187113-e. DOl: 10.1371/journal. pone.0187113.

22. Bardhan PK. Epidemiological features of Helicobacter pylori infection in developing countries. Clin Infect Dis. 1997;25(5):9738. DOI: 10.1086/516067.

23. Lindberg $G$, Hamid SS, Malfertheiner P, Thomsen $\bigcirc \bigcirc$, Fernandez LB, Garisch'J, et al. World Gastroenterology Órganisation

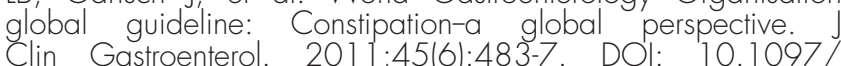
MCG.0b013e31820fb914'.

24. Garza-González E, Perez-Perez Gl, Maldonado-Garza HJ, Bosques-Padilla FJ. A review of Helicobacter pylori diagnosis, treatment, and methods to detect eradication. World j Gastroenterol. 2014;20(6): 1438-49. DOl: 10.3748/wig.v20. i6. 1438.

25. Riba AK, Ingeneri TJ, Strand CL. Improved Histologic Identification of Helicobacter pylori by Immunohistochemistry Using a New Novocastra Monoclonal Antibody. Laboratory Medicine. 201 1;42(1):35-9. DOI: 10.1309/LMAGPAENJKNARI4Z.

26. Lopes Al, Vale FF, Oleastro M. Helicobacter pylori infection - recent developments in diagnosis. World J Gastroenterol. 2014;20(28):9299-313. DOl: 10.3748/wig.v20.i28.9299. 
27. Walker TD, Karemera M, Ngabonziza F, Kyamanywa P. Helicobacter pylori status and associated gastroscopic diagnoses in a tertiary hospital endoscopy population in Rwanda. Trans R Soc Trop Med Hyg. 2014;108(5):305-7. DOI: 10.1093/ trstmh/tru029.

28. Azuma T, Ito S, Sato F, Yamazaki $Y$, Miyaji $H$, Ito $Y$, et al. The role of the HLA-DQA 1 gene in resistance to atrophic gastritis and gastric adenocarcinoma induced by Helicobacter pylori infection. Cancer. 1998;82(6): 1013-8. DOI: 10.1002/(sici) 1097$0142(1998031$ 5)82:6\&lt; 1013 ::aid-cncr2\&gt;3.0.co;2-f.

29. Orhan D, Kalel G, Saltik-Temizel IN, Demir $H$, Bulun A, Karaağaoğlu $E$, et al. Immunohistochemical detection of Helicobacter pylori infection in gastric biopsies of urea breath test-positive and -negative pediatric patients. Turk J Pediatr. 2008;50(1):34-9

\section{Peer Reviewed}

Competing Interests: None declared.

Funding: This study was not funded

Received: 23 October 2020; Accepted: 13 November 2021

Cite this article as Nizeyimana T, Rugwizangoga B, Manirakiza F, Laga CA. Occurrence of Helicobacter Pylori in Specimens of Chronic Gastritis and Gastric Adenocarcinoma Patients: A Retrospective Study at University Teaching Hospital, Kigali, Rwanda. East Afr Health Res J. 2021;5(2):159-163. https://doi. org/10.24248/eahrj.v5i2.667

(C) Nizeyimana et al. This is an open-access article distributed under the terms of the Creative Commons Attribution License, which permits unrestricted use, distribution, and reproduction in any medium, provided the original author and source are properly cited. To view a copy of the license, visit http:// creativecommons.org/licenses/by/4.0/. When linking to this article, please use the following permanent link: https://doi. org/10.24248/eahrj.v5i2.667 